\title{
IMPROVED FORCE ITERATION METHOD BASED ON RATIONAL SHAPE DESIGN SOLVING SELF-STRESS MODES OF CABLE-TRUSS TENSILE STRUCTURE
}

\author{
Su-duo Xue ${ }^{1}$, Jian Lu ${ }^{1, *}$, Xiong-yan $\mathrm{Li}^{1}$ and Ren-jie Liu ${ }^{2}$ \\ ${ }^{1}$ College of Civil and Architecture Engineering, Beijing University of Technology \\ 100 Ping Le Yuan, Chaoyang District, Beijing 100124, China \\ ${ }^{2}$ Civil Engineering College Institute, Yantai University, Yantai, Shandong 264000, China \\ (Corresponding author: E-mail: lujian2020@126.com)
}

\section{A B S T RA C T}

Cable-truss tensile structure is one of the most competitive spatial structures. The shape determination and solving self-stress modes are two key problems in design. Although equilibrium matrix theory can solve the two problems, it need good programming and matrix operation capacity, which is difficult to be mastered by engineers and designers. Other methods are mainly used to solve self-stress modes, but how to design rational shape of structure is not introduced and these methods cannot be directly used in finite element (FEM) software. For these problems, based on existed FEM software, the improved force iteration method based on rational shape is proposed. The new method is based on the topological relation of cable-truss tensile structure, and a simple formula for shape determination was deduced from the rational shape. By studying force iteration method, improved force iteration method is proposed to solve self-stress mode of cable-truss tensile structures. The new method is based on the idea that is shape determination first and then solving self-stress modes, which can rapidly determine rational shape and self-stress mode. And then the feasible prestress can be solved. The new method can be used in FEM software and consider material properties and nonlinearity. Numerical examples show that the new method has a systematic solution flow and high convergence accuracy.

\section{A R T I C L E H I S T ORY}

\begin{tabular}{|c|c|}
\hline Received: & 15 August 2019 \\
\hline Revised: & 19 April 2020 \\
\hline Accepted: & 29 April 2020 \\
\hline
\end{tabular}

\section{K E Y W O R D S}

Cable-truss tensile structure;

Shape determination;

Self-stress modes;

FEM;

Improved force iteration method

\section{Introduction}

Tensegrity structures, which always consist of continuous tension struts and discontinuous compression struts, were proposed by Fuller [1]. The first tensegrity structure was designed by Snelson in 1948 [2], but it was only a structure model [3]. According to the basis of tensegrity concept, Geiger[4] first created the practical meaningful tensegrity which was called cable dome which includes a compression ring in the boundary of a tensegrity structure, the so-called Geiger form dome. The most important features of cable dome are its innovative configuration, lightness and high structural efficiency, which have attracted attention from engineers and designers. Meanwhile, the first cable dome was designed by Geiger for the Olympics in Seoul (1986) [4] After that, many kinds of cable dome structures were built all over the world, such as the Redbrid Arena in Illinois (1988), the Florida Suncoast Dome in ST. Petersburg (1988), the Taoyuan Arena in Taiwan (1993), and the oval plan Levy form cable dome for the Olympics in Georgia (1996) [5]. In addition, the recent cable dome was the National Fitness center in Ejin Horo Banner, Inner Mongolia (2012) [6].

Meanwhile, there are many novel types of tensile structures at home and abroad and the typical type is cable-truss tensile structure (CTTS), such as spoke cable-truss structure [7] and annular crossed cable-truss structure (ACCTS) [8,9], shown in Fig. 1. Cable dome structure is also a kind of CTTS, shown in Fig. 1. CTTS refers to the tension integral structure formed by a series of the same type of planar cable-truss frames according to certain layout principles. The common point of this type structure is that integral structure can be divided into the same type planar cable-truss frame which has the same characteristics including light weight, large stiffness, strong spanning capacity and simple construction. There are some engineering cases of spoke cable-truss structure, such as Foshan Stadium in China, Shenzhen Bao'an Stadium in China, Yueqing Stadium in China [10], Busan Stadium in South Korea [11]. But ACCTS [8,9] is in the stages of theoretical and experimental research and there are no engineering cases.

In the state of zero stress, CTTS is a kind of mechanism without specific shape and bearing capacity. In the state of prestress, it has specific shape and certain stiffness. So, two problems of the paper are proposed: rational shape determination and solving self-stress modes.

As early as 1864, stability judgment method for traditional rigid structures proposed by Maxwell is not suitable [12]. By studying Maxwell criteria and topological relations of tensile structure, the matrix decomposition method was proposed by Pellegrino and Calladine in 1986 [13-15]. Now matrix decomposition method is widely used in shape determination, but matrix decomposition method needs programming and matrix operation to judge whether the shape of structure is rational, which is not easy to be mastered by engineers and designers. So, it is urgent to find a simple method for determining the rational shape of CTTS. Based on the research of CTTS, the paper divides CTTS into planar cable-truss frame, and deduces the simple judgment equation of rational shape from the rational shape of planar cabletruss frame.

For how to solve self-stress modes, based on the flexibility method, Hanaor [16] proposed a unified method for the analysis and prestress design of tensile structures. Pellegrino and Calladine [13-15] proposed the singular value decomposition (SVD) technique to solve the independent self-stress modes. Considering the inherent geometric symmetry of cable domes and based on SVD, Yuan et al. [17,18] proposed the concept of integral feasible prestress modes and proposed a general method that referred to DSVD for solving the problems of shape determination and the initial prestress distribution of various forms of cable dome [19]. Based on the linear adjustment theory, a new numerical algorithm was presented for the initial prestress finding procedure of assemblying cable-strut [20]. Later, Wang et al. [21] proposed a simple method to design the prestress for cable dome with self-weight based on the nodal equilibrium equation after changing the structural self-weight into the nodal force. Tian et al. [22] proposed constrains removed method to solve the self-stress mode of spoke cable-truss structures based on FEM software. Guo et al. [23] innovated a Newton iteration method to update the prestress and a simple method for updating the structural geometry shape under different states. Guo et al. [24] developed a pretension simulation algorithm to find the feasible prestress and based on the fuzzy relationship between prestress and internal force. The existing methods mostly based on equilibrium matrix theory or nodal equilibrium method to solve the self-stress modes of structures. But those methods cannot consider structural deformation and material properties, and cannot use the existing FEM software to solve these problems.

Based on the existed FEM software, rational shape and the basic principle of force iteration method, an improved force iteration method is proposed to solve the self-stress mode of CTTS. The new method first divides CTTS into planar cable-truss frame for simple design, and then according to the unique topological relation of planar cable-truss frame, the internal relationship to maintain its balance is deduced from its rational shape. Secondly, planar cable-truss frame with rational shape can be obtained by using the internal relationship. Finally, the CTTS can be obtained by assembling planar cabletruss frames in reverse.

The layout of the paper is as follows. How to design the rational shape of CTTS is studied in section 2. Based on the basic principle of force iteration method and the features of the existed FEM software, an improved force iteration method is proposed in section 3. In section 4 , three examples are given to verify the feasibility of the new method. In section 5 , the way to solve the feasible prestress under self-weight and external loads is proposed 
and cable dome is taken as an example. Some conclusions are drawn at the end of the paper.

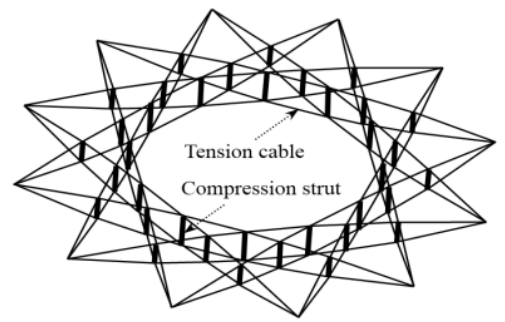

(a) Annular crossed cable-truss structure (ACCTS)

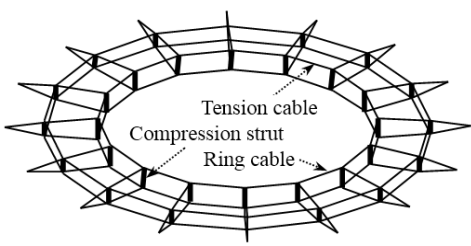

(b) Spoke cable-truss structure

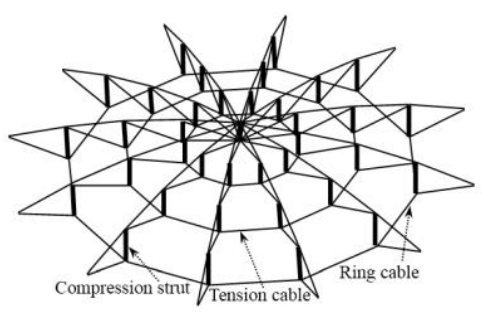

(c) Cable dome structure

Fig. 1 Schematic diagrams of three types of cable-truss tensile structures

\section{The criteria of rational shape design}

\subsection{Annular crossed cable-truss structure (ACCTS)}

ACCTS $[8,9]$ can be simplified into planar cable-truss frame, shown in Fig. 2. Assume that all nodes of the planar cable-truss frame are in equilibrium state, and the derivation process is described in detail. The vertical components are strut, and the others are cable.

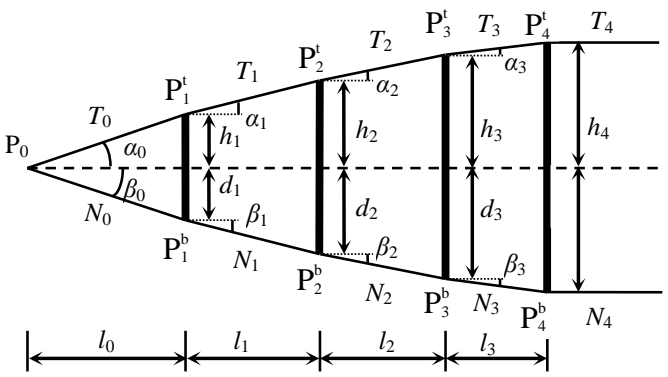

Fig. 2 Diagram of half planar cable-truss frame

Taking the whole structure as the research object, the moment of node $P_{0}$ can be obtained:

$$
T_{4} \cdot h_{4}-N_{4} \cdot d_{4}=0
$$

Taking all upper nodes as the research object, equilibrium equation in horizontal direction of each node is obtained. After simplification, the general equation is obtained:

\section{$T_{4}=T_{i} \cdot \cos \alpha_{i}$}

Similarly, the general equation of each lower node in horizontal direction is obtained:
$N_{4}=N_{i} \cdot \cos \beta_{i}$

Taking all the struts as the research object, and the equilibrium equation of each strut in vertical direction is obtained:

$T_{i} \cdot \sin \alpha_{i}=N_{i} \cdot \sin \beta_{i}$

Substitute Eq. (2) and (3) into Eq. (4), and then obtain Eq. (5):

$T_{4} \cdot \tan \alpha_{i}=N_{4} \cdot \tan \beta_{i}$

Eq. (5) shows that the horizontal force components of the upper and lower chord cables are equal for any planar cable-truss frame with rational shape. Furthermore, the vertical force of each node also keeps the struts in equilibrium state. The horizontal and vertical equilibrium forces keep planar cable-truss frame in integral equilibrium state.

According to geometric relationship, then obtain Eq. (6) and Eq. (7):

$\left\{\begin{array}{l}\tan \alpha_{0}=h_{1} / l_{0} \\ \tan \beta_{0}=d_{1} / l_{0}\end{array}\right.$

$\left\{\begin{array}{l}\tan \alpha_{1}=\left(h_{1}-h_{2}\right) / l_{1} \\ \tan \beta_{1}=\left(d_{1}-d_{2}\right) / l_{1}\end{array}\right.$

From Eq. (5), (6) and (7), then obtain Eq. (8) and (9):

$\frac{\tan \alpha_{0}}{\tan \beta_{0}}=\frac{h_{1}}{d_{1}}=\frac{N_{4}}{T_{4}}$

$\frac{\tan \alpha_{1}}{\tan \beta_{1}}=\frac{h_{2}-h_{1}}{d_{2}-d_{1}}=\frac{N_{4}}{T_{4}}$

Based on Difference Ratio Theorem, and Eq. (10) from Eq. (8) and (9) is obtain:

$\frac{\tan \alpha_{1}}{\tan \beta_{1}}=\frac{h_{2}-h_{1}}{d_{2}-d_{1}}=\frac{h_{1}}{d_{1}}=\frac{h_{2}}{d_{2}}=\frac{\tan \alpha_{0}}{\tan \beta_{0}}=c$

Similarly, the general equation can be written as:

$\frac{h_{1}}{d_{1}}=\frac{h_{2}}{d_{2}}=\frac{h_{3}}{d_{3}}=\frac{h_{4}}{d_{4}}=\cdots=\frac{h_{i}}{d_{i}}=c$

Eq. (11) shows that the ratio of the upper part and lower part of all struts of planar cable-truss frame in a rational shape is a constant $C$. In total, when the ratio of the upper part and lower part of all struts of the planar cable-truss frame is constant $C$, the horizontal force components of the upper and lower chord cables are equal, and planar cable-truss frame is in equilibrium state and has an independent self-stress mode.

Reference [25] can be used to select the rise-span ratio of upper and lower chord cables, and then rational constant $C$ can be obtained.

Meanwhile, the contour of planar cable-truss frame should follow the three curves:

$\left\{\begin{array}{l}y+a x^{2}+b x+c=0 \\ a x^{2}+b y^{2}+c=0 \\ y+a \cosh (x / a)=0\end{array}\right.$

The three curves not only can meet the requirements of drainage slope, but can provide the geometric shapes which can stiffen planar cable-truss frame under prestress. 


\subsection{Cable dome structure and spoke cable-truss structure}

As cable dome structure and spoke cable-truss structure cannot enhance the overall stability and anti-lateral stiffness of the structure by the form of crossed connection like ACCTS, cable dome structure and spoke cable-truss structure enhance the overall stability and anti-lateral stiffness of the structure by adding ring cables (shown in Fig. 1b and Fig. 1c). Cable dome structure and spoke cable-truss structure can be divided into a series of planar cabletruss frames, so their design criteria of rational shape are similar to those of ACCTS. However, when cable dome structure and spoke cable-truss structure are simplified and calculated, it is necessary to replace the ring cable by the equivalent lower chord cables according to the equivalent stiffness principle. The difference between ring cable and equivalent lower chord cable is that the sectional size of cable is different.

Because the calculation process of equivalent lower chord cable of cable dome structure is the same as that of spoke cable-truss structure, the outermost ring cable of cable dome (shown in fig. 1c) can be taken as the research object, and the simplified calculation model of cable dome structure is shown in Fig. 3. The calculation model can be considered as a composite cable-truss structure consisting of three planar cable-truss frames extending along the resultant force lines, including cable-truss frame 212'5, cable-truss frame 322'3'6'6, cable-truss frame 433'4'7'7, respectively. Its contour design can still refer to the shape design criteria of ACCTS.

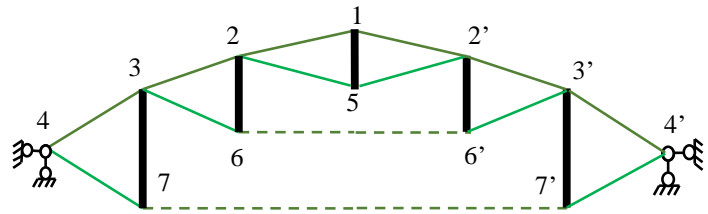

(a) Simplified shape of cable dome structure
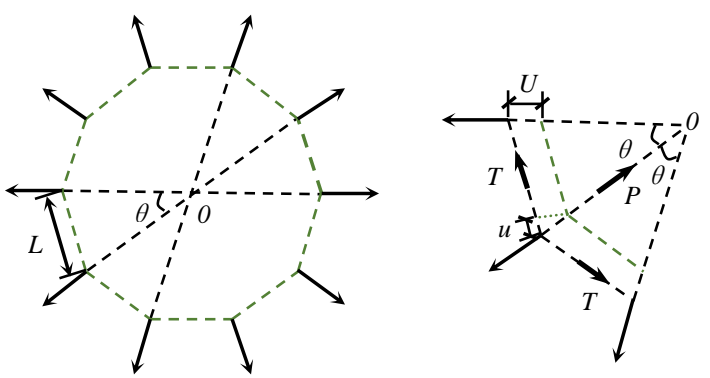

(b) Simplified shape (c) Force diagram of ring cable and of ring cable equivalent lower chord cable

Fig. 3 Simplified calculation diagram of equivalent lower chord cable of cable dome

Assuming elastic modulus, cross-sectional area and length of cable is E, $\mathrm{Ar}$, and L, respectively. The radius of polygon consisting of ring cable is $\mathrm{R}$ and the internal force of ring cable is $\mathrm{T}$. The cross-sectional area, cable force and tensile stiffness of equivalent lower chord able is Aeq, P and EAeq, respectively. The cross-sectional area of equivalent lower chord cable is calculated as follows.

It can be seen from the Fig. $3 \mathrm{c}$ that the relationship between tensile force of ring cable and internal force of equivalent lower chord cable is obtained:

$$
P=2 T \sin \frac{\theta}{2}
$$

The length of ring cable:

$$
L=2 R \sin \frac{\theta}{2}
$$

The elongation of each ring cable is obtained:

$u=\frac{T}{E A_{r}} L=\frac{T}{E A_{r}} 2 R \sin \frac{\theta}{2}=\frac{P R}{E A_{r}}$

According geometric relationship, radial displacement of equivalent lower chord cable can be obtained from the elongation of each cable:

$$
U=\frac{u}{2 \sin (\theta / 2)}=\frac{P R}{2 E A_{r} \sin (\theta / 2)}
$$

So, the internal force of equivalent lower chord cable can be obtained:

$P=\frac{2 E A_{r}}{R} U \sin \frac{\theta}{2}$

From the relationship between force and displacement, P can also simplify into the form of equivalent area Aeq:

$$
P=E A_{e q} \cdot \frac{U}{R}
$$

By comparing Eq. (17) with Eq. (18), the equivalent area can be obtained:

$A_{e q}=2 A_{r} \sin \frac{\theta}{2}$

\section{Solving self-stress modes}

\subsection{The theoretical basis of solving self-stress modes}

Equilibrium theory [13-16] is a common method to solve self-stress of cable-strut tensile structures, and the basic equation is as follows:

$$
\boldsymbol{A} \times \boldsymbol{T}=\boldsymbol{F}
$$

$\boldsymbol{A}$ is equilibrium matrix. $\boldsymbol{T}$ is internal forces of struts. $\boldsymbol{F}$ is the equivalent nodal force vector generated by external loads. Essentially, Eq. (20) is an equilibrium process of internal forces and external loads at each node. By singular value decomposition of the equilibrium matrix $\boldsymbol{A}$, the number of structural self-stress modes can be determined and the self-stress modes of each order can be obtained. However, equilibrium matrix cannot be obtained by the existed FEM software. Generally, equilibrium matrix $\boldsymbol{A}$ needs to be obtained by means of computer programming, which is not convenient to use and not easy to be mastered by designers and engineers. Meanwhile, equilibrium matrix theory cannot consider structural deformation and material properties, and cannot reflect real self-stress modes.

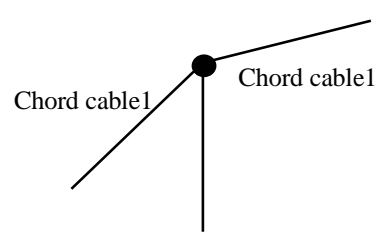

(a) Basic force unit

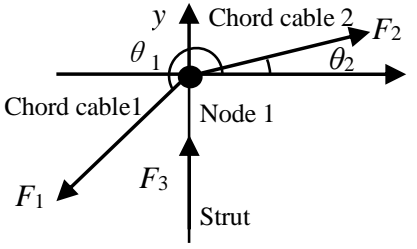

(b) Force condition of node 1
Fig. 4 Basic force unit modal and its force state
Chord cable 2

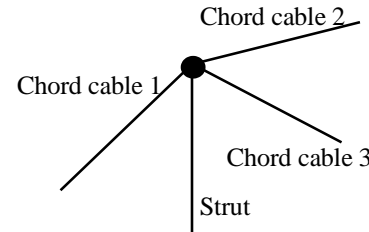

(a) Node and element model

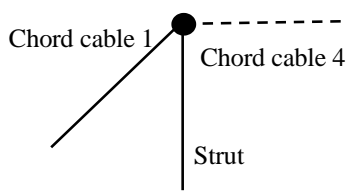

(b) Node model after equivalence
Fig. 5 Basic force modal of and its force state cable dome

Taking basic force unit in Fig. 4 as an example, and its force condition is shown in Fig. 4b. For cable dome structure, the internal forces of chord cable 2 and cable 3 can be equivalent to chord cable 4, shown in Fig. 5, which is similar to basic force unit in Fig. 4. The node equilibrium equation are established by the coordinate system shown in Fig. $4 \mathrm{~b}$, which can be written as the Eq. (21).

As solving self-stress modes, the condition under external loads cannot be considered. Namely, Eq. (21) can be written as Eq. (22). 


$$
\begin{aligned}
& {\left[\begin{array}{ccc}
\cos \theta_{1} & \cos \theta_{2} & 0 \\
\sin \theta_{1} & \sin \theta_{2} & 1
\end{array}\right]\left[\begin{array}{l}
F_{1} \\
F_{2} \\
F_{3}
\end{array}\right]=\left[\begin{array}{l}
P_{1} \\
P_{2}
\end{array}\right]} \\
& {\left[\begin{array}{ccc}
\cos \theta_{1} & \cos \theta_{2} & 0 \\
\sin \theta_{1} & \sin \theta_{2} & 1
\end{array}\right]\left[\begin{array}{l}
F_{1} \\
F_{2} \\
F_{3}
\end{array}\right]=\left[\begin{array}{l}
0 \\
0
\end{array}\right]}
\end{aligned}
$$

$\boldsymbol{A}=\left[\begin{array}{ccc}\cos \theta_{1} & \cos \theta_{2} & 0 \\ \sin \theta_{1} & \sin \theta_{2} & 1\end{array}\right]$

$$
\left\{\bar{F}_{1}, \bar{F}_{2}, \bar{F}_{3}\right\}^{T}=\left\{\frac{\cos _{2}}{\sin \left(\theta_{2}-\theta_{1}\right)}, \frac{\cos _{1}}{\sin \left(\theta_{1}-\theta_{2}\right)}, 1\right\}^{\mathrm{T}}
$$

$F_{1}$ and $F_{2}$ represent internal forces of two chord cables, and $F_{3}$ represents a strut (or linked cable). $\theta_{1}$ and $\theta_{2}$ are the angles between the two chords and the positive direction of the $x$ axis respectively, and $\cos \theta_{1}, \sin \theta_{1}, \cos \theta_{2}$ and $\sin \theta_{2}$ are not zero. Eq. (23) is the coefficient matrix of Eq. (24), and $\boldsymbol{A}$ is a matrix of order $2 \times 3$, and its rank is equal to 2 . So, the basic solution set of Eq. (23) has only one free vector basis, which can be written as Eq. (24). Eq. (22) can be satisfied if $F_{1}, F_{2}$ and $F_{3}$ are set by ratio of Eq. (24). That is, node 1 can keep balance and be in the design shape. The group of proportional relations is called the self-stress mode of basic force unit [22].

When each basic force unit can be in equilibrium state of the design shape under external load and then when the internal forces of all elements are integrated into the vector $\boldsymbol{T}$ of Eq. (20), Eq. (20) can be naturally satisfied. At this point, for the planar cable-truss frame, $\boldsymbol{T}$ is a group of prestress values that can meet the force balance and be in a rational shape. When the external force is zero, the group of prestress values is self-stress mode of planar cabletruss frame. For basic force unit, the internal force of element can be obtained by solving two linear independent equations. But for the integral cable-truss frame, it is difficult to obtain the internal force of each element by solving system of simultaneous equations due to a huge number of nodes.

ANSYS FEM software not only solve basic force unit, but solve integral planar cable-truss frame directly. When solving the basic force unit or planar cable-truss frame, ANSYS software cannot solve equilibrium matrix $\boldsymbol{A}$ in Eq. (20), and cannot directly solve Eq. (21) and (22), but can solve Eq. (25). In FEM software, the element stiffness matrix is obtained first, and then the integral stiffness matrix is assembled (the assembly process of the stiffness matrix is hidden in the background of software). Therefore, the internal forces of the planar cable-truss frame can be obtained through basic force unit.

\section{$\left(\boldsymbol{K}_{E}+\boldsymbol{K}_{G}\right) \boldsymbol{U}=\boldsymbol{F}+\boldsymbol{P}+\boldsymbol{R}$}

For Eq. (25), $\boldsymbol{K}_{E}$ is elastic stiffness matrix. $\boldsymbol{K}_{G}$ is geometry stiffness matrix. $\boldsymbol{U}$ is nodal displacement vector. $\boldsymbol{P}$ is prestress vector of component. $\boldsymbol{R}$ is the unbalanced force vector generated by the higher order terms of $\boldsymbol{U}$ in the solving process. The geometric stiffness matrix $\boldsymbol{K}_{G}$ is related to nodal coordinates and the prestress of members.

When solve the Eq. (25), force iteration method or displacement iteration method can be used [26], and the solution obtained is the solution of Eq. (21) and Eq. (22). For the basic force unit shown in Fig. 4, the convergence speed of force iteration method or displacement iteration method is very fast [26]. Generally, only 3 4 times iterations are needed to achieve high accuracy. According to the simplicity degree of the existed FEM software, the force iteration method is recommended.

\subsection{Improved force iteration method}

According to the force iteration method in section 3.1, it is necessary to improve the force iteration method when solving the self-stress mode of planar cable-truss frame. Taking basic force unit as an example, the specific process is as follows:

(1) First, a group of initial prestress values of $\boldsymbol{F}_{0}=\left[F_{1}, F_{2}, F_{3}\right]$ is assigned to the basic force unit, shown in Fig. 6a;

(2) By using force iteration method to solve the basic force unit in Fig. 6a, the prestress value of basic force unit can be obtained as $\boldsymbol{F}_{1}=\left[F_{1,1}, F_{2,1}, F_{3,1}\right]$. The unbalanced displacement of node 1 is $u_{1}$, iteration process shown in Fig. 6 b. (the 1st subscript represents element number, and the 2nd subscript represents the number of iteration, the same below.)

(3) In the 2nd iteration, rather than substituting $\boldsymbol{F}_{1}=\left[F_{1,1}, F_{2,1}, F_{3,1}\right]$ into the original basic force unit to calculate (iteration process shown in Fig. 6c), but taking one of initial cable force as the basic value (choose $F_{1}$ or $F_{2}$ ). Then updating the prestress of rest elements, the group of updated cable values are $\boldsymbol{F}_{1}^{1}=\left[F_{1,1}^{1}, F_{2,1}^{1}, F_{3,1}^{1}\right]$, which can be written as $\boldsymbol{F}_{1}^{1}=\left[1, F_{2,1} / F_{1,1}, F_{3,1} / F_{1,1}\right] * F_{1}$. The unbalanced displacement of node 1 is $u_{2}\left(u_{2}<u_{1}\right)$, iteration process shown in $6 \mathrm{~d}$. The unbalanced displacement value $u_{2}^{0}$ is equal to $u_{2}$ when nonlinear, dead weight and external load are not considered. After the cable forces are updated, the improved force iteration method can approach the target value gradually and obtain the unbalanced displacement of structure under target prestress. (The superscript represents the result after each iteration and cable forces update, the same below)

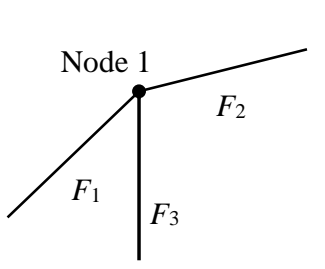

(a) Basic force unit

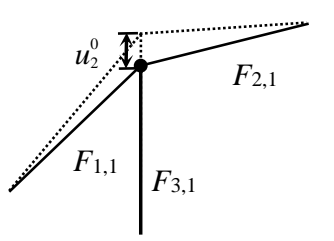

(c) The 2nd iteration of

force iteration method

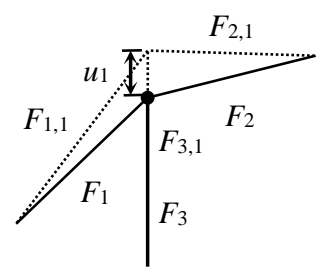

(b) The 1st iteration

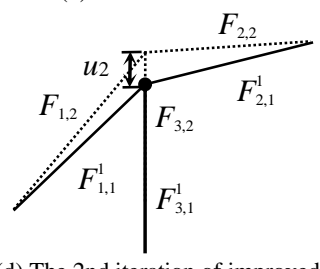

(d) The 2nd iteration of improved

force iteration method
Fig. 6 Schematic diagram of solving process of force iteration method

(4) The convergence criteria of cable force and structural displacement, which is $\left|\boldsymbol{F}_{j}-\boldsymbol{F}_{j-1}\right|<\delta_{1},\left|u_{j}-u_{j-1}\right|<\delta_{2}$ respectively, are used to judge whether the results meet the requirements. ( $\delta_{1}$ and $\delta_{2}$ is convergence accuracy which is equal to 0.001 .) When the last two calculation results satisfy the convergence accuracy requirements, the calculation stops. Otherwise, the calculation continues until the calculation results meet requirements.

3.3. Improved force iteration method based on rational shape to solve selfstress mode of CTTS

Based on FEM software and improved force iteration method, improved force iteration method based on rational shape to solve self-stress mode of CTTS is proposed. The theoretical basis of this method is equilibrium matrix theory, which reflects in the solution process of force iteration method and extends to solve the self-stress mode of planar cable-truss frame.

Because planar cable-truss frame has many nodes and is symmetrical structure, the below several points should be paid more attentions when improved force iteration method is used to update cable force: (a) The element of planar cable-truss structure should be grouped; (b) Assuming that the $i$ th group cable forces $\left(F_{i}\right)$ are the basic values, the ratio values of updating cable forces are according to the ratio of each group cable forces $F_{k}(k$ is not equal to $i$ ) being relative to the $i$ th group cable $F_{i}$ obtained by each iteration calculation; (c) When updating the $i$ th group cable force, directly update the $i$ th group cable force according to the baisc values; (d) After all groups of prestress values are updated and compensated, they can be used as the initial prestress values of the next iteration.

Solving process is as follow:

(1) The simplified model of CTTS is designed by the design criteria of rational shape in section 2, and planar cable-truss frame with rational shape is obtained;

(2) The cable and strut elements of planar cable-truss frame are grouped into $n$ groups, and the initial prestress value is $\boldsymbol{F}_{0}=\left[F_{1,0}, F_{2,0}, \ldots, F_{i, 0}, \ldots, F_{n, 0}\right]$;

(3) Taking $\boldsymbol{F}_{0}$ as the initial prestress condition of the 1st nonlinear iteration, the result of the 1 st iteration is $\boldsymbol{F}_{1}=\left[F_{1,1}, F_{2,1}, \ldots, F_{i, 1}, \ldots, F_{n, 1}\right]$. The displacement of each control node is $\boldsymbol{U}_{1}=\left[u_{1,1}, u_{2,1}, \ldots, u_{i, 1}, \ldots, u_{n, 1}\right]$. By the convergence criteria of force and displacement to judge whether the results meet the Eq. (26), if the results meet Eq. (26), then $\boldsymbol{F}_{1}$ is the self-stress mode, otherwise continue to iterate. 


$$
\left\{\begin{array}{l}
\left|\boldsymbol{F}_{j}-\boldsymbol{F}_{j-1}\right| \leq \delta_{1} \\
\left|\boldsymbol{U}_{j}-\boldsymbol{U}_{j-1}\right| \leq \delta_{2}
\end{array}\right.
$$

$\boldsymbol{F}_{j}$ and $\boldsymbol{F}_{j-1}$ are the $j$ th and $j$-1 th iteration calculation prestress values. $\boldsymbol{U}_{j}$ and $\boldsymbol{U}_{j-1}$ are the $j$ th and $j$-1th iteration calculation displacement values, the same below.

(4) Update cable force (or prestress compensation) on the basis of $\boldsymbol{F}_{1}$. When updating cable force, any group of cable elements in $\boldsymbol{F}_{1}$ can be selected as the reference. If take the $i$ th group cable force as reference, the updating $j$ th group cable force is $F_{j, 1}^{1}=F_{i, 0} \frac{F_{j, 1}}{F_{i, 1}}$, and the updating cable force is $\boldsymbol{F}_{1}^{1}=\left[F_{1,1}^{1}, F_{2,1}^{1}, \ldots, F_{i, 1}^{1}, \ldots, F_{n, 1}^{1}\right] . \boldsymbol{F}_{1}^{1}$ can be further written as Eq. (27) and (28)

$\boldsymbol{F}_{1}^{1}=\left[\frac{F_{1,1}}{F_{i, 1}} F_{i, 0}, \frac{F_{2,1}}{F_{i, 1}} F_{i, 0}, \ldots, \frac{F_{i, 1}}{F_{i, 1}} F_{i, 0}, \ldots, \frac{F_{n, 1}}{F_{i, 1}} F_{i, 0}\right]$

$\boldsymbol{F}_{1}^{1}=\left[\frac{F_{1,1}}{F_{i, 1}}, \frac{F_{2,1}}{F_{i, 1}}, \ldots, 1, \ldots, \frac{F_{n, 1}}{F_{i, 1}}\right] F_{i, 0}$

Taking $\boldsymbol{F}_{1}{ }^{1}$ as the initial prestress condition of the 2 nd nonlinear iteration, the result of the 2nd iteration is $\boldsymbol{F}_{2}=\left[F_{1,2}, F_{2,2}, \ldots, F_{i, 2}, \ldots, F_{n, 2}\right]$. The displacement of each control node is $\boldsymbol{U}_{2}=\left[u_{1,2}, u_{2,2}, \ldots, u_{i, 2}, \ldots, u_{n, 2}\right]$. According to the convergence criteria of force and displacement to judge whether the results meet the Eq. (26), if the results meet Eq. (26), then $\boldsymbol{F}_{2}$ is the self-stress mode, otherwise continue to iterate.

(5) Update cable force on the basis of $\boldsymbol{F}_{2}$. The updating $j$ th group cable force is $F_{j, 2}^{2}=F_{i, 0} \frac{F_{j, 2}}{F_{i, 2}}$, and the updating cable force is $\boldsymbol{F}_{2}^{2}=\left[F_{1,2}^{2}, F_{2,2}^{2}, \ldots, F_{i, 2}^{2}, \ldots, F_{n, 2}^{2}\right] . \boldsymbol{F}_{2}^{2}$ can be further written as Eq. (29) and (30):

$\boldsymbol{F}_{2}^{2}=\left[\frac{F_{1,2}}{F_{i, 2}} F_{i, 0}, \frac{F_{2,2}}{F_{i, 2}} F_{i, 0}, \ldots, \frac{F_{i, 2}}{F_{i, 2}} F_{i, 0}, \ldots, \frac{F_{n, 2}}{F_{i, 2}} F_{i, 0}\right]$

$\boldsymbol{F}_{2}^{2}=\left[\frac{F_{1,2}}{F_{i, 2}}, \frac{F_{2,2}}{F_{i, 2}}, \ldots, 1, \ldots, \frac{F_{n, 2}}{F_{i, 2}}\right] F_{i, 0}$

Taking $\boldsymbol{F}_{2}^{2}$ as the initial prestress condition of the 3rd nonlinear iteration, the result of the 3rd iteration is $\boldsymbol{F}_{3}=\left[F_{1,3}, F_{2,3}, \ldots, F_{i, 3}, \ldots, F_{n, 3}\right]$. The displacement of each control node is $\boldsymbol{U}_{3}=\left[u_{1,3}, u_{2,3}, \ldots, u_{i, 3}, \ldots, u_{n, 3}\right]$. According to the convergence criteria of force and displacement to judge whether the results meet the Eq. (26), if the results meet Eq. (26), then $\boldsymbol{F}_{3}$ is the self-stress mode, otherwise continue to iterate.

(6) $\cdots \cdots$

(7) Similarly, Update cable force on the basis of $\boldsymbol{F}_{k}$. The updating $j$ th group cable force is $F_{j, k}^{k}=F_{i, 0} \frac{F_{j, k}}{F_{i, k}}$, and the updating cable force is $\boldsymbol{F}_{k}^{k}=\left[F_{1, k}^{k}, F_{2, k}^{k}, \ldots, F_{i, k}^{k}, \ldots, F_{n, k}^{k}\right] . \boldsymbol{F}_{k}^{k}$ can be further written as Eq. (31) and (32):

$\boldsymbol{F}_{k}^{k}=\left[\frac{F_{1, k}}{F_{i, k}} F_{i, 0}, \frac{F_{2, k}}{F_{i, k}} F_{i, 0}, \ldots, \frac{F_{i, k}}{F_{i, k}} F_{i, 0}, \ldots, \frac{F_{n, k}}{F_{i, k}} F_{i, 0}\right]$

$\boldsymbol{F}_{k}^{k}=\left[\frac{F_{1, k}}{F_{i, k}}, \frac{F_{2, k}}{F_{i, k}}, \ldots, 1, \ldots, \frac{F_{n, k}}{F_{i, k}}\right] F_{i, 0}$

Taking $\boldsymbol{F}_{k}^{k}$ as the initial prestress condition of the $k+1$ th nonlinear iteration, the result of the $k+1$ th iteration is $\boldsymbol{F}_{k+1}=\left[F_{1, k+1}, F_{2, k+1}, \ldots, F_{i, k+1}, \ldots, F_{n, K+1}\right]$. The displacement of each node is $\boldsymbol{U}_{k+1}=\left[u_{1, k+1}, u_{2, k+1}, \ldots, u_{i, k+1}, \ldots, u_{n, k+1}\right]$.
According to the convergence criteria of force and displacement to judge whether the results meet the Eq. (26), if the results meet Eq. (26), then $\boldsymbol{F}_{k+1}$ is the self-stress mode, otherwise continue to iterate.

(8) Finally, substitute the self-stress mode obtained from planar cabletruss frame into the general FEM model, and further verify whether the selfstress modes obtained from planar cable-truss frame is correct. The self-stress mode is correct if the convergence accuracy is satisfied. Otherwise go back to step (2), and recalculate.

The solving flow chart of improved force iteration method based on rational shape, shown in Fig. 7.

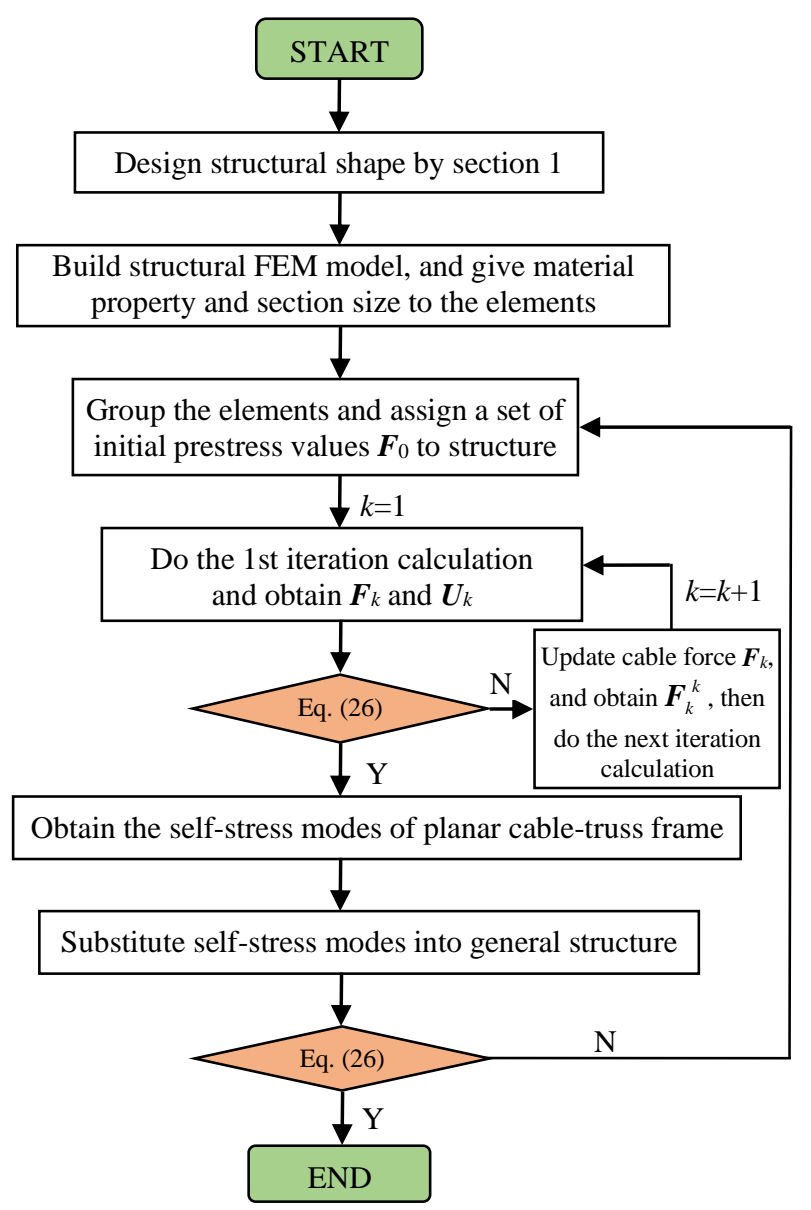

Fig. 7 Flow chart of form-finding of new method

\section{Examples}

\subsection{Annular crossed cable-truss structure}

By the design criteria in section 2, design a ACCTS with a diameter with $100 \mathrm{~m}$ (Radius $R_{1}=50 \mathrm{~m}$ ). According to the daylighting requirements and seating requirements of stadium, the radius $R_{2}$ of the open-air part is $25.08 \mathrm{~m}$. The ring equivalent components are 12 , and a single planar cable-truss frame spans 4 ring equivalent components, whose span is $86.60 \mathrm{~m}$. Firstly, assuming the vector heights of the upper and lower chord cables are $3.662 \mathrm{~m}$ and $5.413 \mathrm{~m}$, respectively. Secondly, assuming the contour of planar cable-truss frame is a certain parabola, and obtain the coordinates of all nodes by numerical calculation. The perspective diagram of ACCTS is shown in Fig. 8. The size of planar cable-truss frame is shown in Fig. 9. Elastic modulus of cable is $1.3 \times 10^{5} \mathrm{Mpa}$. Elastic modulus of strut is $2.06 \times 10^{5} \mathrm{Mpa}$. Poisson's ratio of cable and strut is 0.3 , and cross-sections of cable and strut are shown in Table 1.

The self-stress mode of ACCTS is solved by improved force iteration method based on rational shape. As the stiffness of structural outer ring beam is very large, the constraint between structure and outer ring beam can be considered as rigid constraints. Taking cable force of element 2-4 as the updating basis value, assume that target prestress of element $2-4$ is $240 \mathrm{kN}$ and the prestresses of other cables are $240 \mathrm{kN}$. The results obtained by using the new method are compared with the theoretical values, shown in Table 1 . The theoretical values are obtained by "node equilibrium method" in reference [21]. The iteration processes are shown in Fig. 10. 

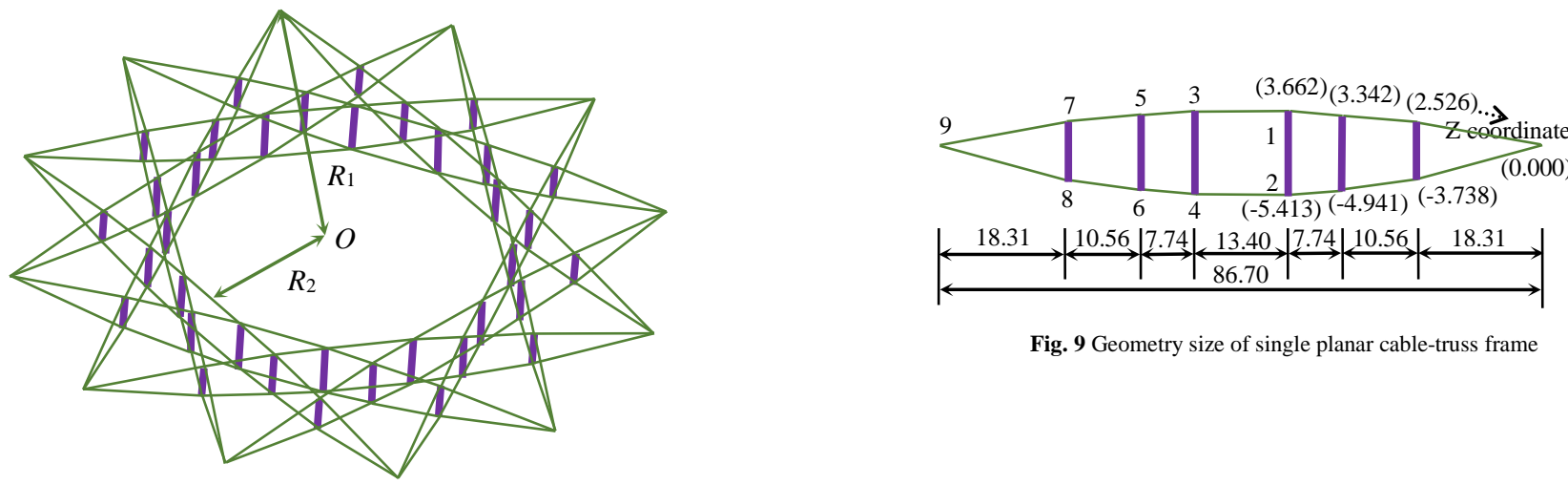

Fig. 9 Geometry size of single planar cable-truss frame

Fig. 8 Annular crossed cable truss structure

Table 1

Prestress distribution of ACCTS Unit: kN

\begin{tabular}{|c|c|c|c|c|c|c|c|c|}
\hline \multirow{2}{*}{$\begin{array}{l}\text { Element } \\
\text { number }\end{array}$} & \multirow{2}{*}{$\begin{array}{l}\text { Cross-section } \\
\left(\mathrm{mm}^{2}\right)\end{array}$} & \multirow{2}{*}{$\begin{array}{l}\text { Theoretical } \\
\text { values }\end{array}$} & \multicolumn{5}{|c|}{ Iteration process of the new method } & \multirow{2}{*}{$\begin{array}{l}\text { error } \\
(\%)\end{array}$} \\
\hline & & & Initial values & $1 \mathrm{st}$ & 2 nd & $3 \mathrm{rd}$ & 4th & \\
\hline $1-3$ & 1495.93 & 354.00 & 240.00 & 266.92 & 348.2 & 354.28 & 354.64 & 0.18 \\
\hline $3-5$ & 1495.93 & 354.30 & 240.00 & 267.14 & 348.49 & 354.56 & 354.91 & 0.17 \\
\hline 5-7 & 1495.93 & 355.66 & 240.00 & 267.74 & 349.27 & 355.35 & 355.71 & 0.01 \\
\hline $7-9$ & 1495.93 & 357.96 & 240.00 & 269.53 & 351.56 & 357.69 & 358.04 & 0.02 \\
\hline $2-4$ & 1930.57 & 240.00 & 240.00 & 185.04 & 235.9 & 239.58 & 239.8 & 0.08 \\
\hline $4-6$ & 1930.57 & 240.45 & 240.00 & 185.38 & 236.33 & 240.03 & 240.25 & 0.08 \\
\hline $6-8$ & 1930.57 & 241.54 & 240.00 & 186.25 & 237.44 & 241.16 & 241.38 & 0.06 \\
\hline $8-9$ & 1930.57 & 244.94 & 240.00 & 188.84 & 240.79 & 244.56 & 244.78 & 0.06 \\
\hline 3-4 & 2578.76 & -29.30 & 240.00 & -22.375 & -28.791 & -29.262 & -29.289 & 0.03 \\
\hline $5-6$ & 2578.76 & -25.36 & 240.00 & -19.393 & -24.957 & -25.366 & -25.39 & 0.11 \\
\hline $7-8$ & 2578.76 & -43.35 & 240.00 & -33.033 & -42.51 & -43.206 & -43.246 & 0.23 \\
\hline
\end{tabular}

Error=abs([new method] $-[$ theoretical values $] /[$ theoretical values $]) \times 100$

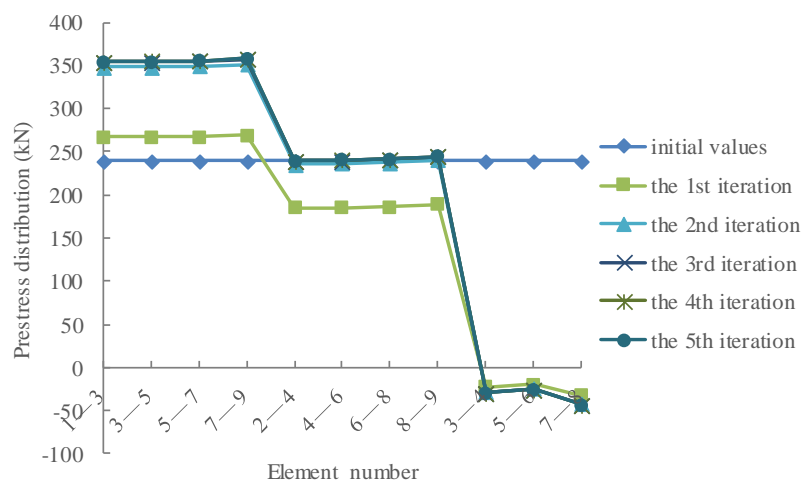

Fig. 10 Trend chart of prestress distribution in iterative process

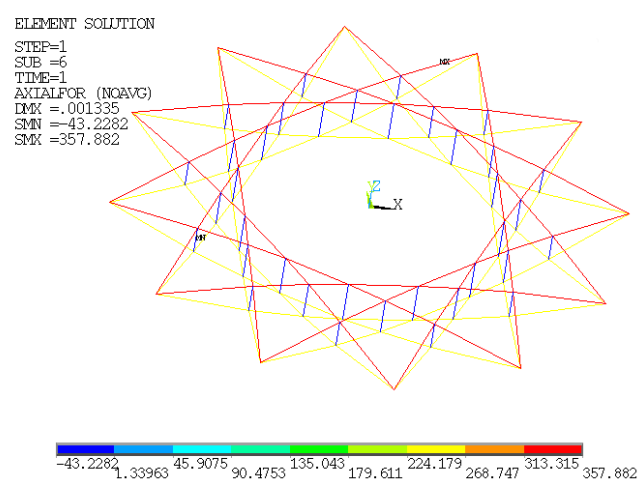

Fig. 11 Calculation results of integral FEM model
Table 2

The change of displacement convergence value in the iteration process

\begin{tabular}{ccccc}
\hline Number of iteration & 1st & 2nd & 3rd & 4th \\
\hline Maximum displacement $/ \mathrm{m}$ & 0.0541 & 0.004 & 0.0014 & 0.0012 \\
\hline
\end{tabular}

It can be seen from Fig.10 that the cable force distribution tends to be stable when the 3rd iteration is carried out, and the cable forces change very slightly when the iteration continues. Meanwhile, it can be seen from Table 1 that the 3rd iteration results are basically equal to the 4th iteration's and the cable force tends to be stable. The maximum error of prestress is $0.23 \%$, which meets engineering accuracy requirement. Displacement convergence values in iteration process are shown in Table 2. Table 2 shows that the errors between the calculation results of the 3rd and 4th displacement and design coordinates are $0.0014 \mathrm{~m}$ and $0.0012 \mathrm{~m}$, respectively. The difference is $0.0002 \mathrm{~m}$. The calculation results of integral FEM model show in Fig. 11 by substituting the self-stress modes obtained from planar cable-truss frame into the integral FEM model, and internal forces and displacement of elements are basically equal to the results obtained from planar cable-truss frame. The example shows that new method has the advantages of fast convergence, high accuracy, stable calculation. The new method can accurately and quickly determine the prestress distribution that meets the design shape requirements.

\subsection{Spoke cable-truss structure}


Taking reference [22] as an example. Spoke cable-truss structure consists of 16 planar cable-truss frames, shown in Fig. 12. The schematic diagram of planar cable-truss structure is shown in Fig. 13. Element 3-4 and 5-6 are compression struts, and others are tension cables. Element 1-3 and 2-4 are equivalent lower chord. The cross-section of cable and strut are $7.069 \mathrm{~mm}^{2}$ and $143.728 \mathrm{~mm}^{2}$. Elastic modulus of cable and strut are $1.8 \times 10^{5} \mathrm{Mpa}$ and $2.06 \times 10^{5} \mathrm{Mpa}$. Poisson's ratio of cable and strut is 0.3 .

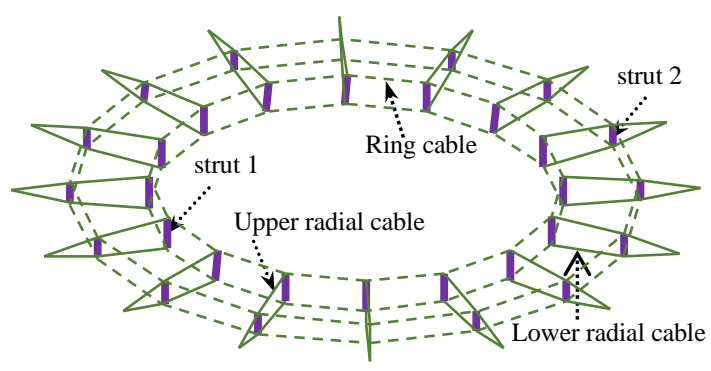

Fig. 12 Spoke Cable-truss Structure

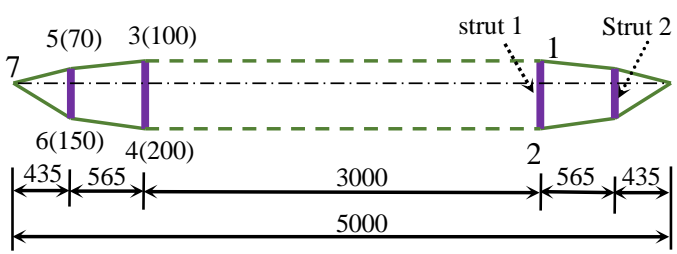

Fig. 13 Size of original cable-truss frame Unit: $\mathrm{mm}$

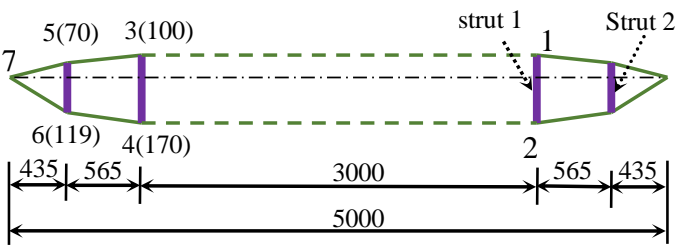

Fig. 14 Size of modified cable-truss frame Unit: mm

By the new method, first judge whether the structural shape is rational, and then solve the self-stress modes. It can be known that the ratio of upper and lower part of strut 1 is $C_{1}=100 / 200=0.5$, and the ratio of upper and lower part of strut 2 is $C_{2}=70 / 150=0.47$. Because $C_{1}$ is not equal to $C_{2}$, structural shape is not rational, which shows that the independent self-stress mode does not exist. The reference [22] judged whether the structure had a self-stress mode by comparing the internal force of strut obtaining from solving the upper chord node 1,3,5 with the internal force of strut obtaining from solving the lower chord node $2,4,6$. If the internal forces of struts obtained from solving the upper and lower nodes are equal, the structure exists a self-stress mode. Otherwise, the self-stress mode does not exist. Compared with the method in reference [22], the new method simplifies the judgment process.

It needs to redesign the structural shape because the original structure does not have self-stress mode. Modified criteria: Generally, the coordinate values of the upper chord nodes are not changed to meet the drainage slope requirements of structure. Meanwhile, the coordinate values of lower chord nodes are generally not allowed to move downward to meet the audience's view and daylighting requirements.

To be the same as the modified geometrical shape of reference [22], the coordinates of upper chord nodes is unchanged, and modified coordinate of node 6 is $119 \mathrm{~mm}$. According to section 2, in order to ensure the original structure has the self-stress mode, the ratio of upper and lower chord lengths of all struts must be guaranteed to be equal. Namely, there exists an $x$ value to make the equation 70/119=100/ $x$ exist and $x$ is the modified coordinate of node 4 , which is equal to $170 \mathrm{~mm}$. Reference [22] uesed the method of "modify the structural coordinate first - then solve the internal forces of components - finally judge whether the shape is rational", and determined that the coordinate of node 4 is equal to $170 \mathrm{~mm}$ through 8 iterations. Compared with the method in reference [22], the new method improves calculation efficiency. The modified geometrical shape is shown in Fig. 14.

The self-stress mode of spoke cable-truss structure is solved by using improved force iteration method based on rational shape. As the stiffness of structural outer ring beam is very large, the constraint between structure and outer ring beam can be considered as rigid constraints. According to Eq. (19) $A_{e q}=2 A_{r} \sin (\theta / 2)\left(\theta=22.5^{\circ}\right)$, the equivalent cross-sections of equivalent lower chord cables are shown in Table 3 .

Table 3

Cross-section equivalent lower chord

\begin{tabular}{ccc}
\hline Element number & Element 1-3 & Element 2-4 \\
\hline Original areas $/ \mathrm{mm}^{2}$ & 7.069 & 7.069 \\
Equivalent areas $/ \mathrm{mm}^{2}$ & 2.758 & 2.758 \\
\hline
\end{tabular}

Taking cable force of element 4-6 as the updating basis, assume that target prestress of element $4-6$ is $11.144 \mathrm{kN}$ and others' are $11.144 \mathrm{kN}$. The results obtaining by using the new method are compared with the theoretical values. The comparative results are shown in Table 4 . The theoretical values are obtained by "node equilibrium method" in reference [22]. The iteration processes are shown in Fig. 15.

Table 4

Prestress distribution of Spoke cable-truss Structure Unit: $\mathrm{kN}$

\begin{tabular}{|c|c|c|c|c|c|c|c|c|c|c|}
\hline \multirow{2}{*}{$\begin{array}{l}\text { Element } \\
\text { number }\end{array}$} & \multirow{2}{*}{$\begin{array}{c}\text { Reference } \\
{[22]}\end{array}$} & \multirow{2}{*}{$\begin{array}{l}\text { Initial } \\
\text { value }\end{array}$} & \multicolumn{7}{|c|}{ Iteration process of the new method } & \multirow{2}{*}{$\begin{array}{l}\text { Error } \\
(\%)\end{array}$} \\
\hline & & & 1 st & 2nd & $3 \mathrm{rd}$ & 4th & 5 th & 6th & 7 th & \\
\hline 4-6 & 11.1440 & 11.114 & 9.385 & 10.193 & 10.668 & 10.912 & 11.048 & 11.091 & 11.115 & 0.26 \\
\hline $6-7$ & 11.5050 & 11.114 & 9.664 & 10.512 & 11.007 & 11.265 & 11.408 & 11.451 & 11.476 & 0.25 \\
\hline $5-7$ & 19.0760 & 11.114 & 12.454 & 15.349 & 17.720 & 18.920 & 18.683 & 18.878 & 18.984 & 0.48 \\
\hline $3-5$ & 18.8599 & 11.114 & 12.295 & 15.165 & 16.873 & 17.886 & 18.472 & 18.663 & 18.769 & 0.48 \\
\hline $1-3$ & 48.2680 & 11.114 & 31.472 & 38.815 & 43.185 & 45.776 & 47.278 & 47.765 & 48.034 & 0.48 \\
\hline $2-4$ & 28.4460 & 11.114 & 23.949 & 26.013 & 27.228 & 27.848 & 28.197 & 28.310 & 28.371 & 0.26 \\
\hline $3-4$ & -1.0000 & 11.114 & -0.761 & -0.871 & -0.934 & -0.969 & -0.988 & -0.994 & -0.998 & 0.20 \\
\hline $5-6$ & -2.0308 & 11.114 & -1.542 & -1.767 & -1.896 & -1.967 & -2.007 & -2.019 & -2.026 & 0.24 \\
\hline
\end{tabular}

Error=abs([the 7th iteration results]-reference [22])/ reference [22] $\times 100$, tensile force of ring cable and internal force of equivalent lower chord cable are converted according to Eq. (13): $P=2 T \sin (\theta / 2) . P$ stands for internal force of equivalent lower chord cable, $T$ stands for tensile force of ring cable, $\theta=22.5^{0}$. The internal forces of ring cable in Table 4 are equivalent 


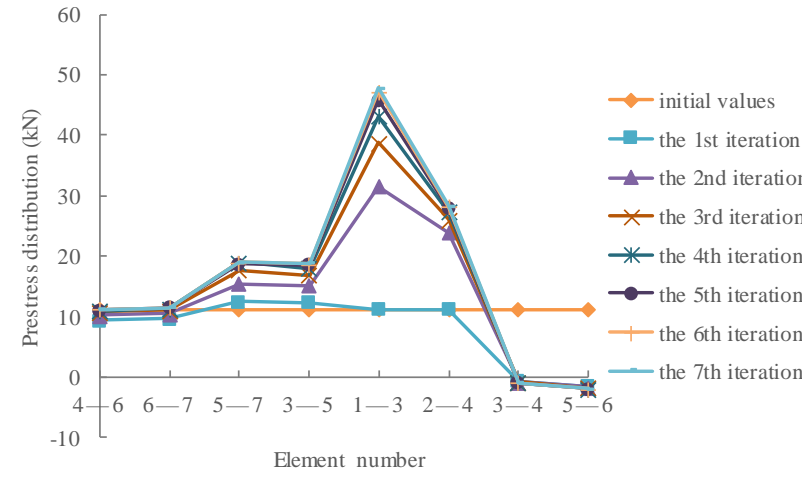

Fig. 15 Trend chart of pretress distribution in iterative process

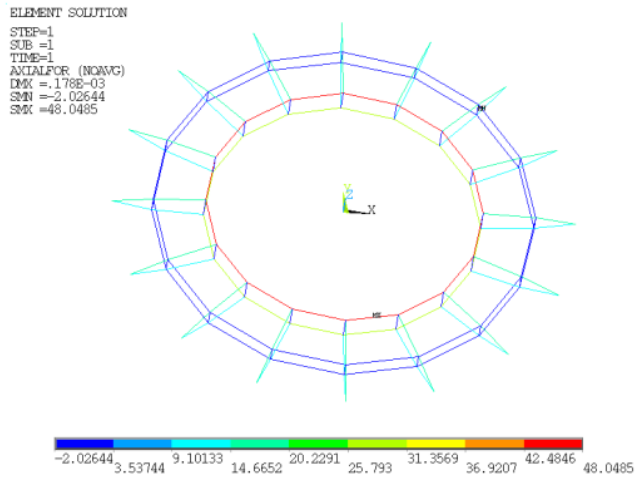

Fig. 16 Calculation results of integral FEM model

Table 5

The change of displacement convergence values in iteration process

\begin{tabular}{cccccccccc}
\hline Number of iteration & 1st & 2nd & 3rd & 4th & 5th & 6th & & & \\
\hline Maximum displacement/m & 0.0168 & 0.0086 & 0.0044 & 0.0022 & 0.0009 & 0.00048 \\
\hline
\end{tabular}

It can be seen from Fig. 15 and Table 4 that the distribution of cable forces tends to be stable when the 4th iteration is accomplished, and the cable force changes very slightly when the iteration continues. According to the comparison between the results of the 7 th iteration and reference [22], the maximum error of prestress force is $0.48 \%$. The displacement convergence values in iteration process are shown in Table 5. Table 5 shows that the errors between the calculation results of the 6 th and 7 th iterations and the design coordinates are $0.00048 \mathrm{~m}$ and $0.00026 \mathrm{~m}$, respectively. The difference of both is $0.00022 \mathrm{~m}$. The calculation results of integral FEM model show in Fig. 16 by substituting the self-stress modes obtained from planar cable-truss frame into the integral FEM model, and internal forces and displacements of element are basically equal to the results obtained from planar cable-truss frame. From the calculation results of force and displacement, it can meet the requirements of engineering accuracy. The example shows that new method has fast design, reasonable shape determination and stable solving self-stress mode.

\subsection{Cable dome structure}

Taking cable dome structure without inner ring as an example, shown in Fig. 17. The structure exists a single self-stress mode, and its span and vector height are $100 \mathrm{~m}$ and $10 \mathrm{~m}$, respectively. The ring equivalent components are 12. Namely, the structure consists of 12 planar cable-truss frames, shown in Fig. 18. Elastic modulus of cable and strut is $1.9 \times 10^{8} \mathrm{kN} / \mathrm{m}^{2}$ and $2.06 \times$ $10^{8} \mathrm{kN} / \mathrm{m}^{2}$, respectively, and its Poisson's ratio is 0.3 . The density of cable and strut is $7.85 \times 10^{3} \mathrm{~kg} / \mathrm{m}^{3}$. Structural size and element number are shown in Fig 18. The cable dome structure in Fig. 17 conforms to the design criteria in section 2, so geometric shape is rational. Namely, the structure has a selfstress mode and makes the structure rigidized.

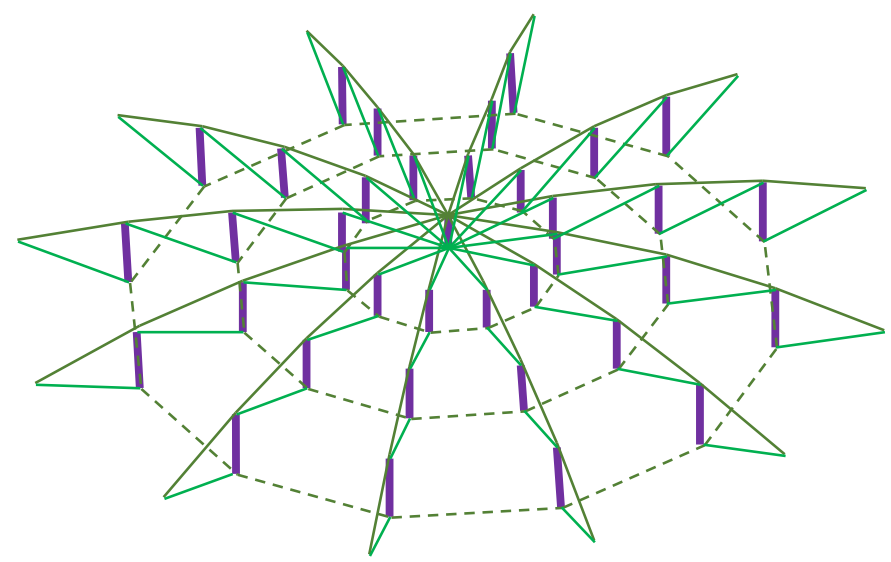

Fig. 17 Three dimensional diagram of cable dome structure without inner ring

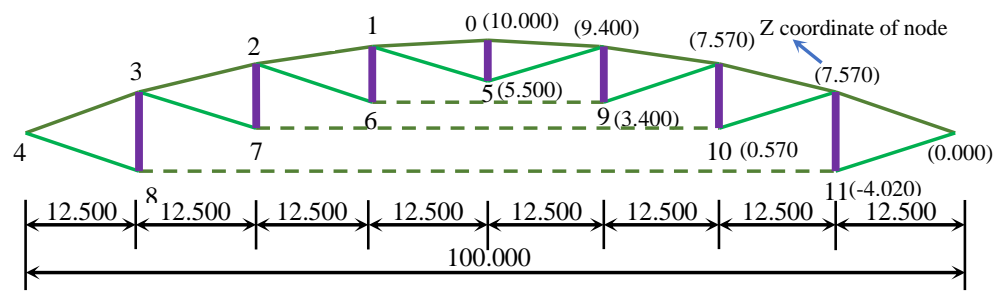

Fig. 18 Element number and geometry size of composited planar cable-truss frame

The self-stress mode of cable dome structure is solved by using improved force iteration method based on rational shape. As the stiffness of structural outer ring beam is very large, the constraints between structure and outer ring beam can be considered as rigid constraints. According to Eq. (19) $A_{e q}=2 A_{r} \sin (\theta / 2) \quad\left(\theta=22.5^{0}\right)$, the equivalent cross-section of equivalent lower chord cable is shown in Table 6. Taking cable force of element 3-4 as the updating basis, assume that target prestress of element $3-4$ is $2734.18 \mathrm{kN}$ and others' are $2734.184 \mathrm{kN}$. The results obtained by using the new method are compared with the theoretical values. The comparative results are shown in Table 7. The theoretical values are obtained by "nodal equilibrium method" in reference [23]. The iteration results of new method are shown in Fig. 19. 
Table 6

Cross-section of equivalent lower chord

\begin{tabular}{ccc}
\hline Element number & $6-9$ & $7-10$ \\
\hline Original area $/ \mathrm{mm}^{2}$ & 6273.00 & 7658.40 \\
Equivalent area/ $\mathrm{mm}^{2}$ & 3247.14 & 3964.28 \\
\hline
\end{tabular}

Table 7

Prestress distribution of cable dome structure Unit: $\mathrm{kN}$

\begin{tabular}{|c|c|c|c|c|c|c|c|c|c|c|}
\hline \multirow{2}{*}{$\begin{array}{l}\text { Element } \\
\text { number }\end{array}$} & \multirow{2}{*}{$\begin{array}{c}\text { Sectional area } \\
/ \mathrm{mm}^{2}\end{array}$} & \multirow{2}{*}{$\begin{array}{l}\text { Ref. [23] } \\
\text { SVD }\end{array}$} & \multicolumn{7}{|c|}{ Iteration process of the new method } & \multirow{2}{*}{$\begin{array}{c}\text { Error } \\
1 \%\end{array}$} \\
\hline & & & Initial & $1 \mathrm{st}$ & 2nd & $3 \mathrm{rd}$ & 4 th & 5 th & 6 th & \\
\hline $0-1$ & 2116.6 & 865.675 & 2734.18 & 945.910 & 779.194 & 864.159 & 866.033 & 866.154 & 866.144 & 0.054 \\
\hline $1-2$ & 3271.2 & 1008.881 & 2734.18 & 1118.900 & 914.313 & 1007.055 & 1009.060 & 1009.202 & 1009.192 & 0.031 \\
\hline $2-3$ & 5349.3 & 1477.825 & 2734.18 & 1646.400 & 1338.940 & 1474.829 & 1477.563 & 1477.765 & 1477.765 & 0.004 \\
\hline $3-4$ & 7658.4 & 2734.18 & 2734.18 & 3042.100 & 2480.223 & 2728.711 & 2733.876 & 2734.281 & 2734.179 & 0.000 \\
\hline $1-5$ & 1193.0 & 139.987 & 2734.18 & 170.300 & 132.719 & 139.706 & 139.8277 & 139.848 & 139.838 & 0.106 \\
\hline $2-6$ & 1193.0 & 459.785 & 2734.18 & 517.860 & 416.668 & 458.650 & 459.3486 & 459.399 & 459.389 & 0.086 \\
\hline $3-7$ & 3271.2 & 1194.105 & 2734.18 & 1326.900 & 1084.882 & 1191.710 & 1194.039 & 1194.241 & 1194.242 & 0.012 \\
\hline $4-8$ & 7658.4 & 3005.301 & 2734.18 & 3351.200 & 2822.578 & 3000.286 & 3006.666 & 3007.071 & 3007.071 & 0.059 \\
\hline $6-9$ & 6273.0 & 842.445 & 2734.18 & 948.686 & 763.194 & 840.468 & 841.740 & 841.818 & 841.818 & 0.075 \\
\hline $7-10$ & 7658.4 & 2202.098 & 2734.18 & 2446.677 & 2000.323 & 2197.910 & 2202.409 & 2202.605 & 2202.605 & 0.023 \\
\hline $8-11$ & 19473.2 & 5526.226 & 2734.18 & 6162.867 & 5190.862 & 5517.761 & 5529.499 & 5530.281 & 5530.086 & 0.070 \\
\hline $0-5$ & 6672.7 & -500.000 & 2734.18 & -599.736 & -470.116 & -499.018 & -499.564 & -499.613 & -499.607 & 0.079 \\
\hline $1-6$ & 1306.9 & -145.676 & 2734.18 & -163.170 & -131.798 & -145.286 & -145.518 & -145.539 & -145.539 & 0.094 \\
\hline $2-7$ & 3543.7 & -355.683 & 2734.18 & -395.470 & -322.407 & -354.809 & -355.488 & -355.538 & -355.538 & 0.041 \\
\hline $3-8$ & 8262.4 & -921.348 & 2734.18 & -1025.30 & -849.264 & -919.183 & -921.036 & -921.158 & -921.148 & 0.022 \\
\hline
\end{tabular}

Error=abs([the 6th iteration results]-reference [23])/ reference [23] $\times 100$, tensile force of ring cable and internal force of equivalent lower chord are converted according to Eq. (13): $P=2 T \sin (\theta / 2) . P$ stands for internal force of equivalent lower chord, $T$ stands for tensile force of ring cable, $\theta=30^{\circ}$. The internal forces of ring cable in Table 7 are equivalent calculated internal forces.

Table 8

The real calculation results of element $0-5$ in the original structure

\begin{tabular}{cccccc}
\hline Iteration number & 1 st & 2nd & 3rd & 4th & 5th \\
\hline New method/kN & -99.956 & -78.353 & -83.170 & -83.261 & -83.269 \\
6 times/kN & $\mathbf{- 5 9 9 . 7 3 6}$ & $\mathbf{- 4 7 0 . 1 1 6}$ & $\mathbf{- 4 9 9 . 0 1 8}$ & $\mathbf{- 4 9 9 . 5 6 4}$ & $\mathbf{- 4 9 9 . 6 1 3}$ \\
\hline
\end{tabular}

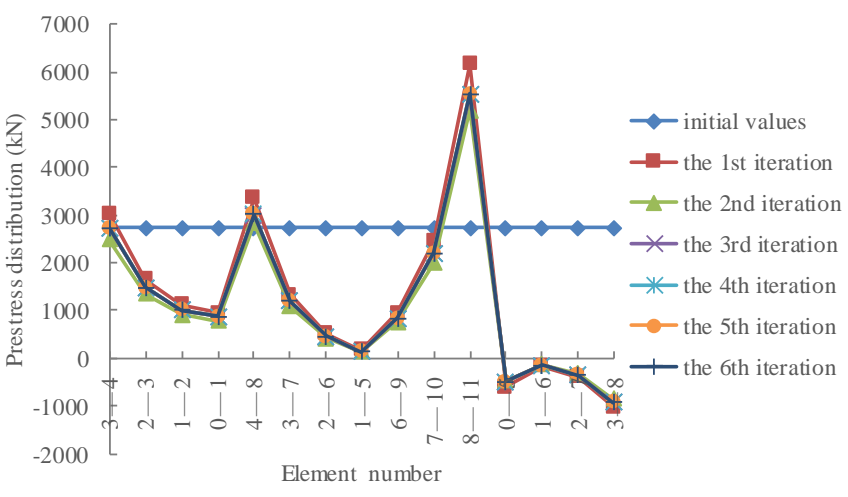

Fig. 19 Trend chart of pretress distribution in iterative process

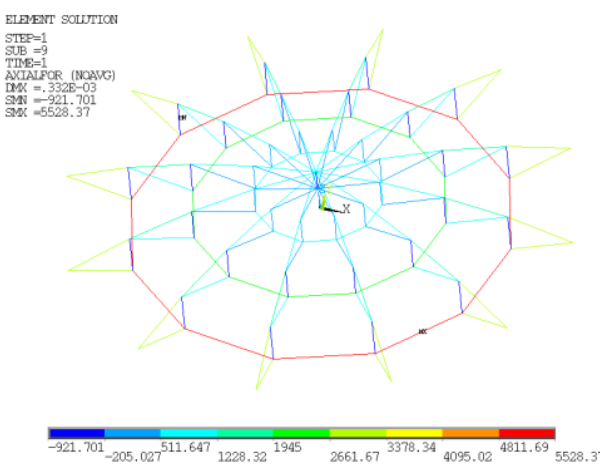

Fig. 20 Calculation results of integral FEM model

Table 9

The change of displacement convergence values in iteration process

\begin{tabular}{ccccccccc}
\hline Iteration number & 1st & 2nd & 3rd & 6th & & 5th & & \\
\hline Maximum displacement/m & 0.2985 & 0.0159 & 0.0051 & 0.0057 & 0.0058 & 0.0058 & \\
\hline
\end{tabular}


It can be seen from Table 7 and Fig. 19 that the cable force distribution tends to be stable when the 4th iteration is accomplished, and the cable force changes very slightly when the iteration continues. According to the comparison between the results of the 6th iteration and SVD, the maximum error of prestress force is $0.106 \%$. The displacement convergence values in iteration process are shown in Table 9. Table 9 shows that the errors between the calculation results of the 5th and 6th and the design coordinates are $0.0058 \mathrm{~m}$ and $0.0058 \mathrm{~m}$, respectively. The difference is zero. The calculation results of integral FEM model show in Fig. 20 by substituting the self-stress modes obtained from planar cable-truss frame into the integral FEM model, and internal forces and displacements of elements are basically equal to the results obtained from planar cable-truss frame. From the calculation results of forces and displacements, it can meet the requirements of engineering accuracy. The example shows that new method has fast design, reasonable shape determination and stable solving self-stress mode. The new method proposes a new approach to solve the self-stress mode of cable dome structure.

\section{The method of solving feasible prestress}

Reference [21-23] can be referred to solve the feasible prestress under self-weight and external loads. Self-weight and external loads can be equivalent to concentrated forces on each node, shown in Fig. 21.

Solving process of equivalent concentrated force [27]:

(1) Firstly, based on SHELL 154 element in ANSYS, the virtual surface units are built on the grid composed of upper chord cable section of cabletruss frame (the virtual unit only transfers load and does not participate in calculation)
(2) Secondly, the load value of membrane surface is obtained according to the literature or specifications.

(3) Finally, all the lower joints of cable-truss frame are constrained along the z-axis, and the constrained reaction forces are the vertical equivalent nodal load of each node. In fact, the method is an approximate method.

Taking reference [23] as an example. To compare with the calculation results in reference [23], the membrane load is $0.6 \mathrm{kN} / \mathrm{m}^{2}$ being the same as reference [23], and the equivalent nodal load of each type of node under selfweight and external loads are shown in Table 10. The compared results of feasible prestress and self-stress mode under self-weight and external loads are shown in Table 11.

Table 10

Equivalent nodal loads under self-weight and external loads

\begin{tabular}{cccccc}
\hline Node number & 0 & 1 & 2 & 3 & 4 \\
Self-weight/kN & -8.274 & -45.826 & -16.104 & -7.479 & -23.071 \\
External loads/kN & -111.700 & -46.818 & -96.854 & -139.520 & -98.025 \\
\hline
\end{tabular}

Table 11 shows that the structural feasible prestress under self-weight changes slightly comparing with its self-stress mode, so the influence of selfweight can be ignored in design. But under the external loads of $0.6 \mathrm{kN} / \mathrm{m}^{2}$, the structural feasible prestress changes dramatically, so the influence of external loads on the structure should be considered in the actual design.

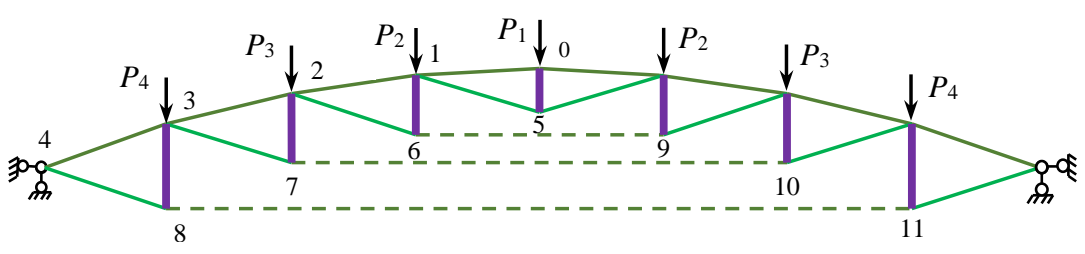

Fig. 21 Applying method of equivalent nodal loads

Table 11

The feasible Prestess under self-weight and external loads Unit: $\mathrm{kN}$

\begin{tabular}{|c|c|c|c|c|c|c|c|c|c|c|c|c|c|c|c|}
\hline Element & $0-1$ & $1-2$ & $2-3$ & $3-4$ & $1-5$ & $2-6$ & $3-7$ & $4-8$ & $6-9$ & $7-10$ & $8-11$ & $0-5$ & $1-6$ & $2-7$ & $3-8$ \\
\hline no self-weight & 866.14 & 1009.19 & 1477.76 & 2734.17 & 139.83 & 459.38 & 1194.24 & 3007.07 & 841.81 & 2202.60 & 5530.08 & -499.60 & -145.54 & -355.54 & -921.15 \\
\hline Self-weight & 697.64 & 810.60 & 1320.00 & 2639.00 & 110.40 & 505.32 & 1260.90 & 3115.10 & 925.47 & 2325.00 & 5727.70 & -949.42 & -361.38 & -115.29 & -396.09 \\
\hline External loads & 528.59 & 607.77 & 1020.90 & 2339.20 & 76.98 & 410.91 & 1270.30 & 3455.90 & 752.42 & 2340.80 & 6353.20 & -925.60 & -286.64 & -84.57 & -286.31 \\
\hline
\end{tabular}

\section{Conclusions}

The paper proposes "Improved force iteration method based on rational shape design solving self-stress mode of cable-truss tensile structure". The conclusions are as follows. According to the topology of CTTS, the internal relation of maintaining the structural balance is obtained based on the rational shape of planar cable-truss frame. This special relation can be used to complete the fast design of planar cable-truss frame (the designed structure has an independent self-stress mode) or to determine whether the geometric shape of the existing cable-truss structure is rational or not. And then assemble the planar cable-truss frame to form the spatial CTTS. Finally, the way to solve feasible prestress is proposed. The examples show that the new method has the advantages of systematic design and solution flow, high accuracy, fast convergence and stable calculation. Meanwhile, the new method can be used in FEM software, which is easy to learn for engineers and designers. The new method offers a new approach for form-finding and design of CTTS.

\section{Acknowledgements}

The authors would like to acknowledge the financial support of the National Natural Science Foundation of China (51778017), the financial support of the National Natural Science Foundation of China (51878014), the Natural Science Foundation of Beijing Municipality (8172011).

\section{References}

[1] Fuller R.B. "Synergetics explorations in the geometry of thinking". London: Macmillan Pbulishing Co., Inc, 1975.

[2] Snelson K. "The art of tensegrity. International Journal Space Structure", $27(2$ and 3), 71-80, 2012.

[3] Motro R., "Tensegrity: Structural Systems for the Future", London: Krogan Page Science, 2003.

[4] Geiger D.H., Stefaniuk A., and Chen D., "The design and construction of two cable domes for the Korean Olympics", Shells, membrane and space frames, proceedings IASS symposium, Japan, 1986, Vol. 2, pp. 265-272.

[5] Levy M.P., "The Georgia Dome and beyond: Achieving light weight-long span structures", Spatial, lattice and tension structures, proceedings IASS-ASCE international symposium, New York, 1994, pp. 560-562.

[6] Ge J.Q., Zhang A.L., Liu X.G., Zhang G.J., Ye X.B., Wang S., and Liu X.C., "Analysis of tension form-finding and whole loading process simulation of cable dome structure", Journal of Building Structures, 33(4), 1-11, 2012.

[7] Deng H., Jiang Q.F., and Kwan A.S.K., "Shape finding of incomplete cable-strut assembles containing slack and prestressed elements", Computers and Structures, 83, 1767-79, 2005.

[8] Liu R.J., Li X.Y., Xue S.D., Marijke M., and Ye J.H., "Experimental and numerical research on Annular Crossed Cable-Truss Structure under cable rupture", Earthquake Engineering and Engineering Vibration, 16(3), 557-569, 2017.

[9] Xue S.D., Liu R.J., Li X.Y., and Marijke M., "Concept proposal and feasibility verification of the annular crossed cable-truss structure", International Journal of Steel Structures, 17(4) 1549-60, 2017.

[10] Deng H., Zhang M.R., Liu H.C., Dong S.L., Zhang Z.H., and Chen L.Q., "Numerical analysis of the pretension deviations of novel Crescent-shaped tensile canopy structural system", Engineering Structures, 119, 24-33, 2016.

[11] Jeon B.S., and Lee J.H., "Cable membrane roof structure with oval opening of stadium for 2002 FIFA world Cup in Busan". In: Proceedings of sixth Asian-Pacific conference on shell and spatial structures, South Korea; 2000, Vol. 2, pp.1037-1042.

[12] Maxwell, J.C., "On the calculation of the equilibrium and stiffness of frames", Phil. Mag, 27, 294-299, 1864.

[13] Pellegrino S., "Structural computations with the singular value decomposition of the equilibrium matrix", International Journal of Solids and Strutures, 30(21), 3025-35, 1993. 
[14] Pellegrino S., and Calladine C.R., "Matrix analysis of statically and kinematically indeterminate frameworks", International Journal of Solids and Strutures, 22(4), 409-428, 1986.

[15] Calladine C.R., and Pellegrino S., "First-order infinitesimal mechanisms", International Journal of Solids and Strutures, 27(4), 505-15, 1991.

[16] Hanaor A., "Prestressed pin-jointed structures with the singular value decomposition of the equilibrium matrix", International Journal of Solids \& Strutures, 30(21), 3025-3035, 1993.

[17] Yuan X.F., and Dong S.L., "Nonlinear analysis and optimum design of cable domes", Engineering Structures, 24(7), 965-977, 2002.

[18] Yuan X.F., and Dong S.L., "Integral feasible prestress of cable domes", Computers and Structures, 81(21), 211-219, 2003

[19] Yuan X.F., Chen L.M., and Dong S.L., "Prestress design of cable domes with new forms", International Journal of Solids and Strutures, 44(9), 2773-2782, 2007.

[20] Zhang L.M., Chen W.J., and Dong S.L., "Initial prestress finding procedure and structural performance research for Levy cable dome based on linear adjustment theory", Journal of Zhejiang University Science A, 8(9), 1366-72, 2007.

[21] Wang Z.H., Yuan X.F., and Dong S.L., "Simple approach for force finding analysis of circular Geiger domes with consideration of self-weight", Journal of Construtional Steel Research, 66(2), 317-322, 2010.

[22] Tian G.Y., Guo Y.L., Wang Y.H., Wang X.A., and Jiang L.X., "Constraints removed method for self-stress mode problem of spokestructures", Spatial Structure, 15(04), $38-43+16,2009$.

[23] Guo J.M., and Jiang J.Q., "An algorithm for calculating the feasible pre-stress of cablestruts structure", Engineering Structures, 118(1), 228-39, 2016.

[24] Guo J.M., and Zhou D., "Pretension simulation and experiment of a negative Gaussian curvature cable dome", Engineering Structures, 127, 737-747, 2016.

[25] Shen S.Z., Xu C.B., and Zhao C., "Suspension structure design", Beijing, China Architecture \& Building Press, 17-19, 2006.

[26] Guo Y.L., and Tian G.Y., "Cable structure system, design theory and construction control", Beijing, Science Press, 2014.

[27] Chen Z.H., Liu H.B., Zhou T., and Qu X.Z., "Parametric calculation and analysis of spatial structure APDL", Beijing, China Water and Power Press, 2009. 